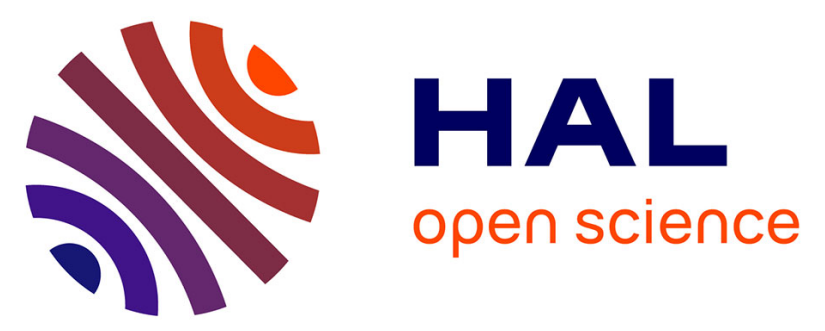

\title{
Early Myocardial Dysfunction and Benefits of Cardiac Treatment in Young X-Linked Duchenne Muscular Dystrophy Mice
}

Marie Vincenti, Charlotte Farah, Pascal Amedro, Valerie Scheuermann, Alain Lacampagne, Olivier Cazorla

\section{To cite this version:}

Marie Vincenti, Charlotte Farah, Pascal Amedro, Valerie Scheuermann, Alain Lacampagne, et al.. Early Myocardial Dysfunction and Benefits of Cardiac Treatment in Young X-Linked Duchenne Muscular Dystrophy Mice. Cardiovascular Drugs and Therapy, In press, 10.1007/s10557-021-07218-7 . hal-03264628

\section{HAL Id: hal-03264628 \\ https://hal.science/hal-03264628}

Submitted on 28 Sep 2021

HAL is a multi-disciplinary open access archive for the deposit and dissemination of scientific research documents, whether they are published or not. The documents may come from teaching and research institutions in France or abroad, or from public or private research centers.
L'archive ouverte pluridisciplinaire HAL, est destinée au dépôt et à la diffusion de documents scientifiques de niveau recherche, publiés ou non, émanant des établissements d'enseignement et de recherche français ou étrangers, des laboratoires publics ou privés. 


\title{
Early Myocardial Dysfunction and Benefits of Cardiac Treatment in Young X-Linked Duchenne Muscular Dystrophy Mice
}

\author{
Marie Vincenti ${ }^{1,2} \cdot$ Charlotte Farah $^{1,3} \cdot$ Pascal Amedro $^{1,2} \cdot$ Valerie Scheuermann $^{1} \cdot$ Alain Lacampagne ${ }^{1}$. \\ Olivier Cazorla ${ }^{1}$
}

\begin{abstract}
Context Duchenne muscular dystrophy (DMD) is associated with a progressive alteration in cardiac function.

Objective The aim of this study was to detect early cardiac dysfunction using the high sensitive two-dimensional speckletracking echocardiography (2D strain) in $m d x$ mouse model and to investigate the potential preventive effects of the S107 ryanodine receptor (RyR2) stabilizer on early onset of DMD-related cardiomyopathy.

Methods and Results Conventional echocardiography and global and segmental left ventricle (LV) 2D strains were assessed in male $m d x$ mice and control C57/BL10 mice from 2 to 12 months of age. Up to 12 months of age, $m d x$ mice showed preserved myocardial function as assessed by conventional echocardiography. However, global longitudinal, radial, and circumferential LV 2D strains significantly declined in $m d x$ mice compared to controls from the 9 months of age. Segmental 2D strain analysis found a predominant alteration in posterior, inferior, and lateral LV segments, with a more marked impairment with aging. Then, $m d x$ mice were treated with S107 in the drinking water at a dose of $250 \mathrm{mg} / \mathrm{L}$ using two different protocols: earlier therapy from 2 to 6 months of age and later therapy from 6 to 9 months of age. The treatment with S107 was efficient only when administered earlier in very young animals (from 2 to 6 months of age) and prevented the segmental alterations seen in non-treated $m d x$ mice.

Conclusions This is the first animal study to evaluate the therapeutic effect of a drug targeting early onset of DMD-related cardiomyopathy, using 2D strain echocardiography. Speckle-tracking analyses revealed early alterations of LV posterior segments that could be prevented by 4 months of RyR 2 stabilization.
\end{abstract}

Keywords Heart failure $\cdot$ Duchenne muscular dystrophy $\cdot$ Dilated cardiomyopathy $\cdot 2 \mathrm{D}$ strain $\cdot$ Speckle-tracking echocardiography

Alain Lacampagne and Olivier Cazorla jointly supervised this work.

Alain Lacampagne

alain.lacampagne@inserm.fr

$\triangle$ Olivier Cazorla

olivier.cazorla@inserm.fr

1 PHYMEDEXP, University of Montpellier, INSERM, CNRS, University Hospital, CHU Arnaud de Villeneuve, 34295 Montpellier, France

2 Pediatric and Congenital Cardiology Department, M3C Regional Reference CHD Centre, University Hospital, Montpellier, France

3 FATH-IREC, Université Catholique de Louvain, Brussel, Belgium

\section{Background}

Duchenne muscular dystrophy (DMD) is the most common type of muscular dystrophy, affecting 1 in 3500 boys, with a genetic X-linked recessive transmission and leading to the absence of dystrophin in all muscles. Skeletal muscle weakness is an early manifestation of DMD. Respiratory failure has long been the most common cause of death in young DMD patients due to diaphragm weakness [1]. With the support of mechanical ventilators, patients with DMD have extended their life expectancy. Progressive dilated cardiomyopathy is now the main cause of mortality in patients with DMD [2]. Cardiomyopathy usually occurs within the second decade. Its early detection, prevention, and treatment stand as one of the most challenging clinical research issues in children with DMD [3]. 
Advanced imaging techniques, such as cardiac magnetic resonance imaging, Doppler tissue imaging or two-dimensional (2D) speckle-tracking echocardiography (STE), and cardiac distortion, have shown cardiac dysfunction as early as the age of 8 [4-6]. Development of new ultrasound technologies has become a valuable tool to better characterize cardiac structure and function both in humans and animals $[5,7,8]$. Our team has recently conducted a prospective controlled study of 108 children, which established the alteration of global left ventricular (LV) 2D strain in children with DMD despite normal LV function [9]. We also found a significant interaction of age with DMD and global longitudinal 2D strain. However, further studies are requested to use speckle-tracking analysis as a reliable surrogate end point for heart failure in this population.

Among animal models of DMD, the X-linked muscular dystrophy $(m d x)$ mouse model has been extensively used to investigate the pathophysiology and test new therapies for DMD [10], with muscular dysfunction similar to human patients [11]. Using conventional ultrasound measures, cardiac dysfunction usually appears at a late stage after 12-month-old [12]. However, LV localized inflammation and fibrosis have been described as early as 4 months of age in $m d x$ mice [13]. The use of STE imaging has allowed to quantitatively measure myocardial strain and strain rate as potentially sensitive markers for early myocardial dysfunction in $m d x$ mice. Li et al. showed that peak systolic global strain analysis was a feasible and reproducible method to detect LV dysfunction in male (and female) $m d x$ mice [8]. The LV segmental STE analysis remains to be performed to detect early cardiac dysfunction and eventually preferential regional cardiac dysfunction. Screening of the contractile defaults of the heart by regional 2D-STE is useful to detect subclinical myocardial dysfunction prior to the development of delayed cardiomyopathy [14]. Moreover, pharmacologic treatment of early deleterious events has to be tested to analyze its impact on in vivo regional cardiac function.

Dystrophin is a cytoskeleton protein that limits sarcolemma mechanical stresses developed during repeated cycles of muscle contraction-relaxation [15]. Among several pathophysiological pathways, alteration in $\mathrm{Ca}^{2+}$ homeostasis is well described and recognized in dystrophin-deficient myopathy [16]. Our group has shown that $\mathrm{Ca}^{2+}$ leaks during diastole from the sarcoplasmic reticulum (SR) is due to progressive ryanodine receptor type 2 (RyR2) nitrosylation and depletion of the regulatory protein FKBP12.6 [12]. This results in increased cytosolic $\mathrm{Ca}^{2+}$ and contributes to trigger cardiac arrhythmias and remodeling in DMD. Preventing the depletion of FKBP12.6 from the RyR2 complex with the $\mathrm{Ca}^{2+}$ channel stabilizer S107 ("rycal") inhibited the $\mathrm{SR} \mathrm{Ca}^{2+}$ leak, inhibited aberrant depolarization in isolated cardiomyocytes, and prevented arrhythmias in vivo.
The impact of S107 on cardiac contractile function remains to be determined.

The aim of the present study was (1) to perform a longitudinal analysis of the global and regional longitudinal, radial, and circumferential LV $2 \mathrm{D}$ strains in $m d x$ and wildtype (WT) mice from 2- to 12-month-old and (2) to test the effect of the S107 RyR2 stabilizer, on early onset of DMDrelated cardiomyopathy.

\section{Methods}

\section{Animal Model}

Experiments were conducted in accordance with the European directive for the protection of animals used for scientific purposes and were approved by the ethical committee (Comité d'éthique pour l'expérimentation animale Languedoc-Roussillon, $\mathrm{n}^{\circ}$ CEEA-LR-12078).

Male WT mice (C57BL/10ScSnJ), designed as WT, were purchased from Harlan Laboratory (Gannat, France). Male $m d x$ mice (C57BL/10ScSnDmd $m d x / \mathrm{J})$, designed as $m d x$, were obtained from a colony maintained in the local animal facility (Plateau Central d'Elevage et d'Archivage, Montpellier, France). Animals were housed conventionally in controlled humidity and temperature, operating on $12 \mathrm{~h}$ of light and dark cycle with food and water available ad libitum. A first set of animals (WT, $\mathrm{n}=12 ; m d x, \mathrm{n}=12$ ) underwent cardiac monitoring using conventional echocardiography and 2D-STE, for an overall period of 1 year. Since the $m d x$ mouse model is a model with mild disease progression, death is not expected during the 1-year study period [10]. Two other sets of $m d x$ mice were treated with S107 diluted in drinking water $(25 \mathrm{mg} / 100 \mathrm{~mL})$ as we previously reported [12], either between 2 and 6 months of age $(n=10)$ or between 6 and 9 months of age $(n=9)$. Sonographer in charge of the study analyses was blinded of mice's group.

\section{Echocardiography}

Cardiac function was evaluated in vivo by $2 \mathrm{D}$ transthoracic echocardiography using a high-frequency ultrasound system (Vevo 2100, Visualsonics, Toronto, Canada) equipped with a $30 \mathrm{MHz}$ probe operating at a frame rate of 200-250 per second and providing high resolution images. Echocardiography was performed by a single sonographer (MV) blinded from mice group and treatment. A posteriori analyses were performed blinded from mice group and treatment using VevoLab software. All measurements were averaged from a minimum of three cycles and followed the standards of the American Society of Echocardiography and the Vevo 2100 guidelines. 
Mice were anesthetized using isoflurane (3\% for induction; $1.5 \%$ sedation). Animals were placed in a dorsal position on a heated platform to maintain physiological body temperature (36-38 ${ }^{\circ} \mathrm{C}$; rectal thermometer monitoring). Heart rate was controlled ( $>400$ beats/min; ECG legs electrodes) with adjustment of level of anesthesia as necessary.

\section{Offline Analysis}

\section{Conventional Echocardiography Indexes}

M-mode images were obtained using LV short-axis view at the mid papillary muscle level in order to assess the following conventional ultrasound indexes of LV morphology and systolic function: LV ejection fraction (LVEF), LV shortening fraction (LVSF), LV mass, LV end diastolic diameter, and LV posterior wall diastolic thickness. Doppler-mode was used in the four-chamber view to assess diastolic function as mitral inflow with peak early diastolic filling (E-wave) and late diastolic filling (A-wave) velocities, E/A ratio. Early diastolic velocities of the medial mitral annulus (E') were measured by pulsed-wave Doppler tissue imaging and E/E' ratio was calculated.

\section{D Strain Analyses}

For 2D strain studies, B mode LV cine loops of short-axis at the mid LV level and long-axis with scan head placed optimized for a clear view of both the apex and the outflow tract of LV were recorded. Three cardiac consecutive and stable cycles were selected. After manual tracing of the LV borders, the VevoLab software automatically detected the movement of the entire myocardial wall (from the endocardium to the epicardium) and therefore defined the areas of interest and divided the LV into 6 segments per view (longaxis segments: basal anterior, mid anterior, apical anterior, apical posterior, mid posterior, and basal posterior segments; short-axis segments: anterior, septal anterior, septal posterior, inferior, posterior, and lateral). In poorly detected segments, the sonographer readjusted the endocardial contour until better detection was obtained. Whenever the tracking quality was not considered acceptable, the related segments were excluded from the analysis and reported as "poor tracking quality" missing data.

Longitudinal LV 2D strain was analyzed using longaxis cine loops. Circumferential and radial LV 2D strains analyses were obtained from short-axis cine loops. For each deformation (longitudinal, circumferential, and radial), segmental peak systolic strains were averaged to obtain the global peak systolic strain. We also pooled the number of hypokinetic segments in each deformation at each time-point to assess the evolution of LV regional dysfunction. Finally, we explored whether the changes in global peak systolic strain were due to alterations of preferential segments. Segments that were altered transiently only at one age were not considered. Altered peak systolic strain (hypokinetic segment or global strain) was defined as significant lower absolute strain value in $m d x$ than in WT mice.

\section{Myocardial Effects of S107 Treatment}

Myocardial effect of S107 treatments was assessed by comparing the results of global and regional 2D strain of these $m d x$-S107 groups to age-matched non-treated $m d x$ mice and WT mice.

\section{Immunoblot Analyses}

All $m d x$-S107 mice were sacrificed at the end of each S107 treatment after echocardiographic evaluation. The LV was dissected, quick frozen in liquid nitrogen, and stored at $-80{ }^{\circ} \mathrm{C}$. Myocardial RyR2 expression was studied, as described previously [17]. Solubilized proteins in nonreducing Laemmli buffer were separated using SDS-PAGE electrophoresis and were revealed overnight with primary antibodies (RyR2, rabbit, homemade; GAPDH, mouse, Abcam 8245). Bands were revealed and quantified with the Odyssey system (LI-COR Biosciences, Lincoln, Nebraska). Protein content was expressed relative to GAPDH content. We compared the expression of RyR2 in $m d x+\mathrm{S} 107$ to agematched $m d x$ controls and to 12 months WT mice.

\section{Statistics}

Statistics were performed using StatView 5.0 (SAS Institute, Cary, NC). Data are presented as the mean \pm SEM. Differences were assessed with the one-way or two-way ANOVA when appropriate. When significant interactions were found, a Bonferroni post-hoc test was applied with $\mathrm{p}<0.05$.

\section{Results}

\section{Conventional and 2D Strain Analyses of Cardiac Function in $m d x$ Mice}

Results of conventional ultrasound indexes and 2D strain analyses from the age of 2 to 12 months, in $12 \mathrm{mdx}$ mice and their controls, are reported in Tables 1 and 2. From 6 months of age, $m d x$ mice showed smaller hearts (reduced LV mass associated with smaller LV internal diameter; Table 1). However, systolic and diastolic function parameters did not differ between $m d x$ and WT mice up to 12 months (Table 1; Fig. 1A). Thus, conventional echocardiography indicates that cardiac function is normal between $m d x$ and WT mice. 
Table 1 Morphological and conventional echocardiographic parameters in wild-type (WT) and mdx mice from 2-to 12-month-old

\begin{tabular}{|c|c|c|c|c|c|c|c|}
\hline & & $\begin{array}{l}\text { WT } \\
(n=12)\end{array}$ & $\begin{array}{l}m d x \\
(\mathrm{n}=12)\end{array}$ & & & $\begin{array}{l}\text { WT } \\
(\mathrm{n}=12)\end{array}$ & $\begin{array}{l}m d x \\
(\mathrm{n}=12)\end{array}$ \\
\hline \multirow[t]{4}{*}{ Body weight (g) } & 2 months & $20.8 \pm 0.5$ & $25.0 \pm 0.5^{*}$ & \multirow[t]{4}{*}{ Heart rate (bpm) } & 2 months & $479 \pm 9$ & $460 \pm 14$ \\
\hline & 6 months & $35.7 \pm 1.2$ & $32.2 \pm 0.6^{*}$ & & 6 months & $436 \pm 12$ & $444 \pm 8$ \\
\hline & 9 months & $42.6 \pm 2.0$ & $32.0 \pm 0.5^{*}$ & & 9 months & $445 \pm 8$ & $504 \pm 11 *$ \\
\hline & 12 months & $44.6 \pm 2.6$ & $31.6 \pm 0.6^{*}$ & & 12 months & $444 \pm 8$ & $493 \pm 7 *$ \\
\hline \multirow[t]{4}{*}{$\mathrm{LVm} / \mathrm{BW}$} & 2 months & $4.5 \pm 0.2$ & $3.8 \pm 0.2 *$ & \multirow[t]{4}{*}{ LV mass (mg) } & 2 months & $93 \pm 5$ & $94 \pm 4$ \\
\hline & 6 months & $4.5 \pm 0.3$ & $3.8 \pm 0.2$ & & 6 months & $159 \pm 8$ & $124 \pm 10^{*}$ \\
\hline & 9 months & $3.4 \pm 0.2$ & $3.7 \pm 0.2$ & & 9 months & $140 \pm 6$ & $119 \pm 7^{*}$ \\
\hline & 12 months & $3.6 \pm 0.2$ & $3.9 \pm 0.3$ & & 12 months & $156 \pm 10$ & $125 \pm 10^{*}$ \\
\hline \multirow[t]{4}{*}{ Ejection fraction (\%) } & 2 months & $71.9 \pm 2.3$ & $65.7 \pm 3.0$ & \multirow[t]{4}{*}{ Fractional shortening $(\%)$} & 2 months & $40.5 \pm 1.9$ & $35.9 \pm 2.2$ \\
\hline & 6 months & $56.9 \pm 1.8$ & $59.9 \pm 2.2$ & & 6 months & $29.6 \pm 1.2$ & $31.4 \pm 1.5$ \\
\hline & 9 months & $61.8 \pm 1.9$ & $62.9 \pm 3.0$ & & 9 months & $32.8 \pm 1.3$ & $33.7 \pm 2.2$ \\
\hline & 12 months & $61.9 \pm 2.8$ & $54.6 \pm 3.5$ & & 12 months & $54.6 \pm 3.5$ & $28.1 \pm 2.3$ \\
\hline \multirow[t]{4}{*}{$\mathrm{LV}$ posterior wall $(\mathrm{mm})$} & 2 months & $0.76 \pm 0.05$ & $0.71 \pm 0.03$ & \multirow[t]{4}{*}{ LV interior diameter $(\mathrm{mm})$} & 2 months & $3.40 \pm 0.08$ & $3.55 \pm 0.09$ \\
\hline & 6 months & $0.93 \pm 0.05$ & $0.91 \pm 0.05$ & & 6 months & $4.06 \pm 0.08$ & $3.64 \pm 0.10^{*}$ \\
\hline & 9 months & $0.92 \pm 0.04$ & $0.96 \pm 0.05$ & & 9 months & $3.94 \pm 0.05$ & $3.43 \pm 0.10^{*}$ \\
\hline & 12 months & $0.94 \pm 0.08$ & $0.93 \pm 0.06$ & & 12 months & $3.96 \pm 0.10$ & $3.62 \pm 0.18$ \\
\hline \multirow[t]{4}{*}{ E/A ratio } & 2 months & $1.39 \pm 0.09$ & $1.39 \pm 0.03$ & \multirow[t]{4}{*}{ E/E' ratio } & 2 months & $22.4 \pm 1.7$ & $23.4 \pm 1.5$ \\
\hline & 6 months & $1.38 \pm 0.08$ & $1.30 \pm 0.05$ & & 6 months & $26.3 \pm 1.0$ & $23.9 \pm 0.9$ \\
\hline & 9 months & $1.17 \pm 0.04$ & $1.23 \pm 0.10$ & & 9 months & $21.3 \pm 1.2$ & $24.6 \pm 1.5$ \\
\hline & 12 months & $1.21 \pm 0.04$ & $1.70 \pm 0.59$ & & 12 months & $24.2 \pm 1.2$ & $24.1 \pm 2.0$ \\
\hline
\end{tabular}

Body weight (BW), LV ejection fraction (LVEF), LV shortening fraction (LVSF), LV mass, LV end diastolic diameter (LVEDd), LV posterior wall diastolic diameter (LVPWd); mitral inflow with peak early filling (E-wave) and late diastolic filling (A-wave) velocities, E/A ratio; early diastolic velocities of the medial mitral annulus (E') measured by pulsed-wave Doppler tissue imaging; E/E' ratio. * $P<0.05$ mdx versus WT at the same age

Table 2 Global 2D-strain analyses in wild-type (WT) and $m d x$ mice

\begin{tabular}{llll}
\hline & & $\begin{array}{l}\text { WT } \\
(\mathrm{n}=12)\end{array}$ & $\begin{array}{l}m d x \\
(\mathrm{n}=12)\end{array}$ \\
\hline Longitudinal global peak systolic strain $(\%)$ & 2 months & $-18.2 \pm 1.8$ & $-20.1 \pm 0.6$ \\
& 6 months & $-19.3 \pm 0.4$ & $-20.6 \pm 1.2$ \\
Radial global peak systolic strain $(\%)$ & 9 months & $-20.2 \pm 0.8$ & $-18.5 \pm 0.9$ \\
& 12 months & $-19.7 \pm 0.6$ & $-17.2 \pm 0.8^{*}$ \\
Circumferential global peak systolic strain (\%) & 2 months & $38.7 \pm 2.8$ & $34.1 \pm 1.0$ \\
& 6 months & $31.6 \pm 2.9$ & $32.1 \pm 2.7$ \\
& 9 months & $39.8 \pm 2.9$ & $36.2 \pm 2.3$ \\
& 12 months & $42.9 \pm 2.6$ & $29.7 \pm 3.1^{*}$ \\
& 6 months & $-26.4 \pm 0.9$ & $-24.0 \pm 0.8^{*}$ \\
& 9 months & $-24.2 \pm 1.5$ & $-23.7 \pm 0.7$ \\
& 12 months & $-27.9 \pm 1.2$ & $-25.0 \pm 1.5$ \\
\hline
\end{tabular}

${ }^{*} \mathrm{P}<0.05 m d x$ versus WT at the same age
Global 2D peak systolic strains decreased in $m d x$ mice from 9 months of age and became significantly lower than controls at 12 months of age in the longitudinal, radial, and circumferential deformations, suggesting early onset of cardiac dysfunction (Fig. 1B-D, Table 2). At the age of 
Fig. 1 Conventional M-mode echocardiography and 2D-STE imaging in WT and $m d x$ mice at ages of 2, 6, 9, and 12 months. Ejection fraction, $E F(\mathbf{A}), \mathrm{LV}$ longitudinal global strain (B), LV radial global strain $(\mathbf{C})$, and LV circumferential global strain (D) were compared between WT and $m d x$ mice at different ages. ( $n=12$ animals/group), 2-way ANOVA, ${ }^{\mathrm{P}}<0.05, m d x$ versus WT mice at the same age
A
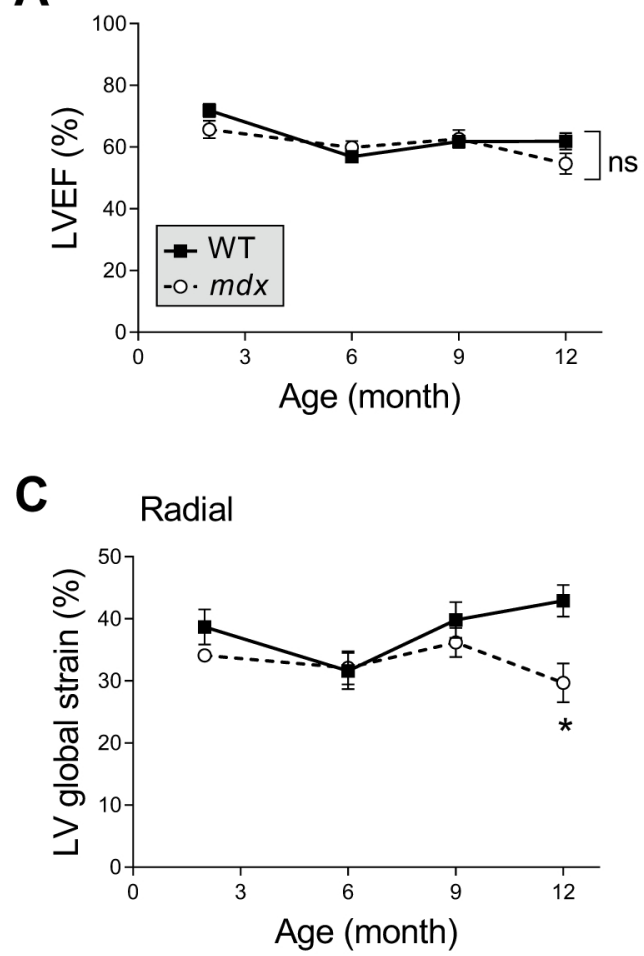

B Longitudinal

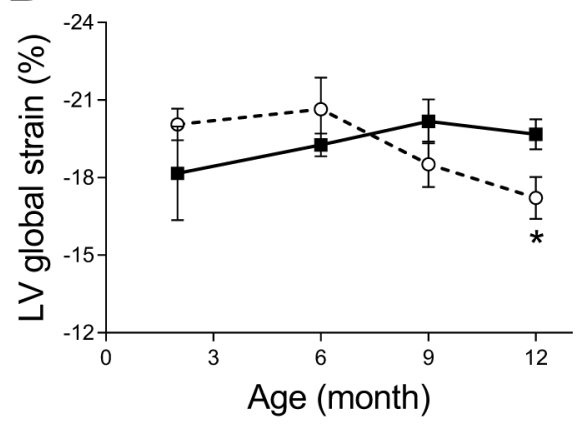

D Circumferential

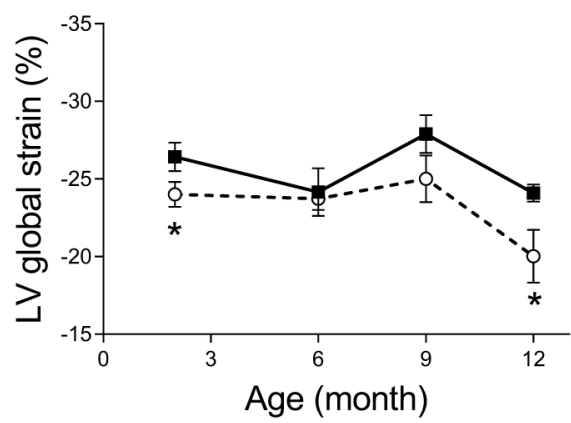

2 months, the LV circumferential strain was significantly lower in $m d x$ mice compared with WT mice (Fig. 1D).

\section{High-Frequency Ultrasound STE Imaging Detects Regional Cardiac Dysfunction in Young $m d x$ Mice}

The number of hypokinetic segments obtained in each view at the different ages is presented in Fig. 2A. Most of the hypokinetic segments were observed with the radial and circumferential strains. At the age of 6 months, hypokinetic segments were localized in the posterior wall and then extended to the lateral wall with age. At the age of 12 months, four out of the six segments of the radial strain and three out of the six segments of the circumferential strain were hypokinetic in $m d x$ compared with WT. Among all segments analyzed, we detected five segments of particular interest because of homogeneously and continuously impaired: the longitudinal mid posterior, the radial inferior and posterior, and the circumferential posterior and lateral segments. The longitudinal mid posterior strain (Fig. 2B) and the radial inferior strain (Fig. 2C) decreased significantly from 9 months of age in $m d x$ compared with WT. The radial posterior strain (Fig. 2D) decreased earlier from 6 months of age in $m d x$ compared with WT. Finally, the circumferential posterior and lateral strains (Fig. 2E and F, respectively) were already lower by 2 months of age in $m d x$ mice.

\section{Effect of Treatment of SR Ca ${ }^{2+}$ Leak (S107) on Global and Regional Cardiac Dysfunction in Young $\mathbf{m d x}$ Mice}

We treated $m d x$ mice just before the onset of decrease of global strain from 6 to 9 months of age (3 months of treatment). The global longitudinal $(-19.4 \pm 1.0 \%)$, radial $(32.5 \pm 1.9 \%)$, and circumferential $(-21.6 \pm 1.8 \%)$ peak systolic strains of $m d x+\mathrm{S} 107$ were not different from the nontreated $m d x$ group at 9-month-old evaluation.

Figure 3 represents the 2D strain segmental results at 9 months of age on WT mice, non-treated $m d x$ mice, and $m d x+\mathrm{S} 107$ mice treated from 6 to 9 months of age. The treatment had no effect on the number of hypokinetic segments as assessed by 2D-STE (Fig. 3A). Similarly, the treatment had no effect on the peak systolic strain of the five segments early altered in $m d x$ mice (Fig. 3B-F). The only segment showing an improvement with $\mathrm{S} 107$ was the radial posterior segment whose peak systolic strain was similar to WT mice $(42.0 \pm 5.5 \%$ in $m d x+\mathrm{S} 107 v s .43 .6 \pm 4.2 \%$ in WT, $\mathrm{p}=0.80)$ and tended to be higher when compared with nontreated $m d x$ mice $(30.1 \pm 3.7 \%, \mathrm{p}=0.06)$ (Fig. 3D).

Then, we treated $m d x$ mice as early as possible from 2 to 6 months of age (4 months of treatment). The global longitudinal $(-18.5 \pm 1.1 \%)$, radial $(34.4 \pm 3.1 \%)$, and circumferential $(-23.7 \pm 1.8 \%)$ peak systolic strains of $m d x+$ S107 were not different from the non-treated $m d x$ group at 6-month-old evaluation. 
Fig. 2 Segmental strain analysis in WT and $m d x$ mice at the ages of 2, 6, 9, and 12 months. A Number of hypokinetic segments from the six segments obtained in longitudinal (Long), radial (Rad), and circumferential view in $m d x$ mice at 2 (light grey), 6 (light grey with black frame), 9 (dark grey with black frame), and 12 (black) months of age. TOTAL is the sum of hypokinetic segments obtained in the three views (out of 18 segments). The upper panel is a drawing illustrating in black, the localization of the segments altered with aging. B-F Evolution with age of the longitudinal posterior-mid strain (B), the radial inferior (C) and posterior (D) strains, and the circumferential posterior $(\mathbf{E})$ and lateral (F) strains in WT (line, black square) and $m d x$ (dash line, open circle) mice ( $\mathrm{n}=12$ animals/group). 2-way ANOVA, $* \mathrm{P}<0.05$, mdx versus WT mice at the same age

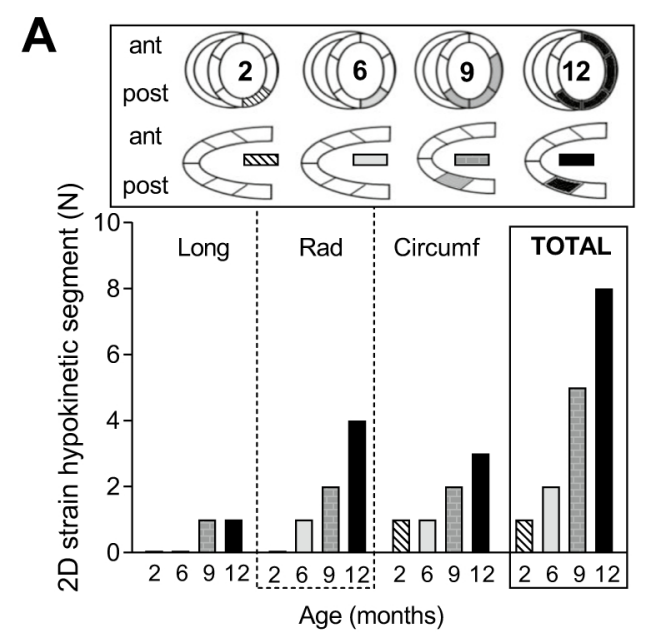

B
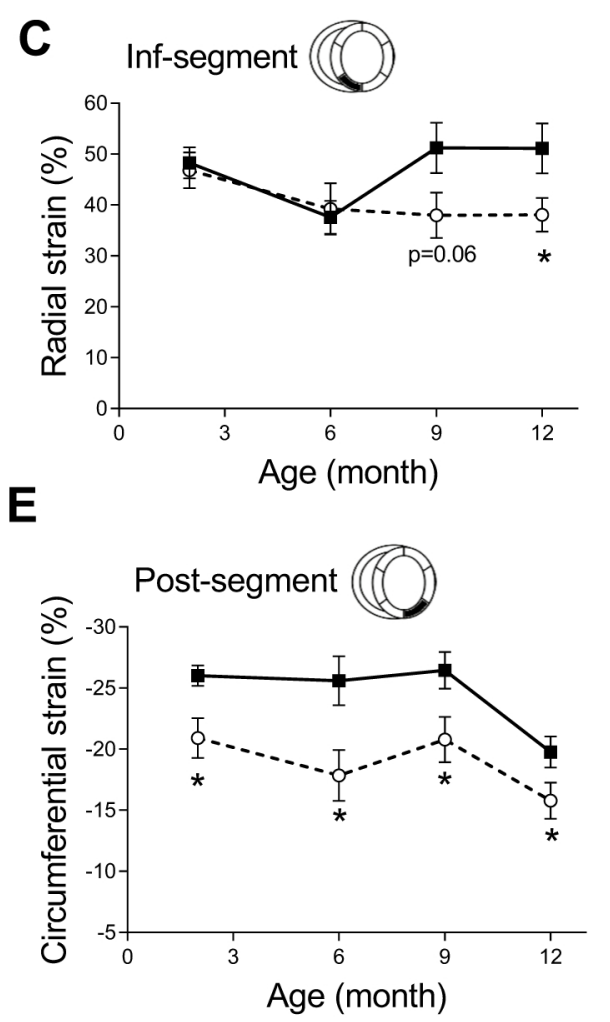
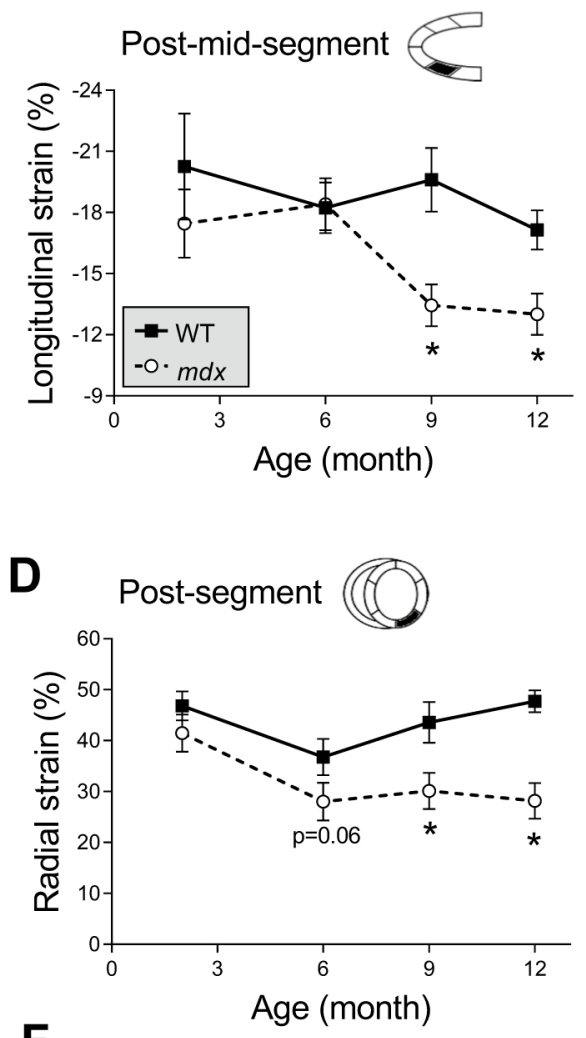

$\mathbf{F}$

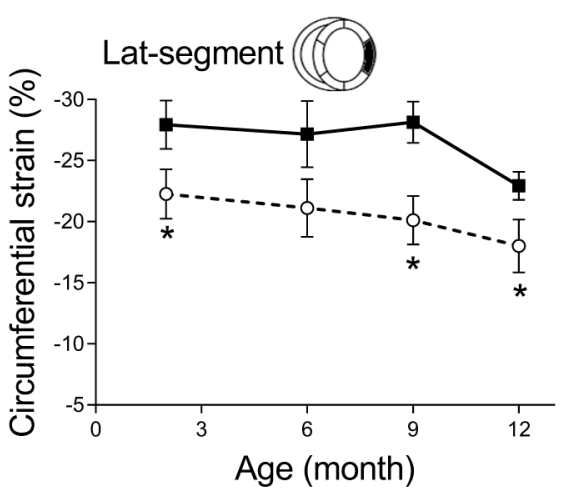

Figure 4 shows the 2D strain segmental results at 6 months of age on WT mice, non-treated $m d x$ mice, and $m d x+\mathrm{S} 107$ mice treated from 2 to 6 months of age. At the age of 6 months, treatment with S107 prevented the development of hypokinetic segments in $m d x$ mice (Fig. 4A). At this age, the significant decreases in radial posterior strain (Fig. 4D) and circumferential posterior strain (Fig. 4E) observed in $m d x$ mice compared to WT mice were not seen in $m d x+\mathrm{S} 107$ mice. The maximal effect of S107 was observed in the radial posterior segment (Fig. 4D; peak systolic strain value $=43 \pm 3 \%$ in $m d x+\mathrm{S} 107$ mice $v s .27 \pm 3 \%$ in non-treated $m d x$ mice $(\mathrm{p}<0.001)$ and $37 \pm 3 \%$ in WT mice $(\mathrm{p}=0.86))$.

\section{Effect of the Treatment of SR Ca ${ }^{2+}$ Leak on RyR2 Macromolecular Complex}

Figure 5 represents the expression of RyR2, the target of S107 treatment, in WT, $m d x$, and two $m d x$-S107 groups. The amount of RyR2 was decreased in 6-monthold $(0.19 \pm 0.03, \mathrm{p}=0.04)$ and 9 -month-old $(0.20 \pm 0.03$, $\mathrm{p}=0.08) m d x$ mice compared to WT $(0.33 \pm 0.08)$. The treatment with $\mathrm{S} 107$ prevented this RyR2 decrease only if administered early in $m d x$ mice (from 2 months of age). 
Fig. 3 Pharmacologic inhibition of RyR2 leak on regional systolic strain alterations in $m d x$ mice. Three months of treatment with $\mathrm{S} 107$ from the age of 6 to 9 months did not prevent regional alterations in $m d x$ mice measured at 9 months of age. A Number of hypokinetic segments from the six segments obtained in longitudinal (Long), radial ( $\mathrm{Rad}$ ), and circumferential view in $m d x$ mice (light grey) and $m d x+\mathrm{S} 107$ mice (black) compared with WT mice. TOTAL is the sum of hypokinetic segments obtained in the three views (out of 18 segments). The upper panel is a drawing illustrating the protocol. B-F Longitudinal posterior-mid strain (B), radial inferior (C) and posterior (D) strains, and circumferential posterior $(\mathbf{E})$ and lateral $(\mathbf{F})$ strains in WT (black square, $\mathrm{n}=12$ ), $m d x$ (open circle, $\mathrm{n}=12$ ), and $m d x+\mathrm{S} 107$ (grey circle, $\mathrm{n}=9$ ) mice, one-way ANOVA $* p<0.05$
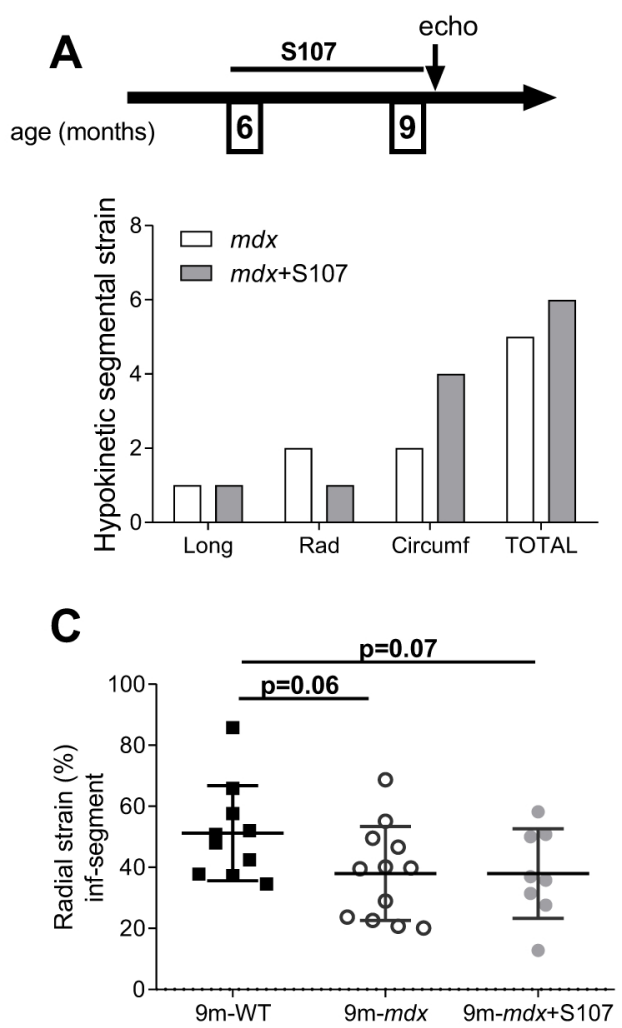

E

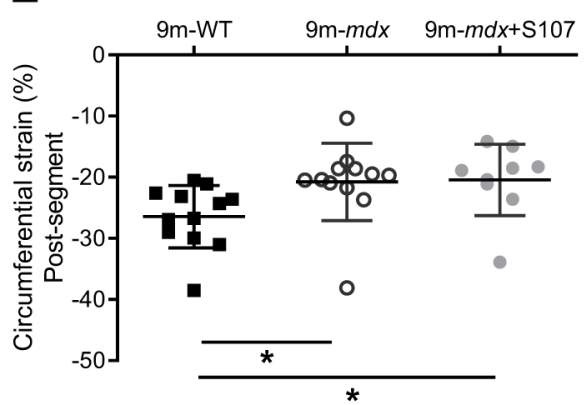

B

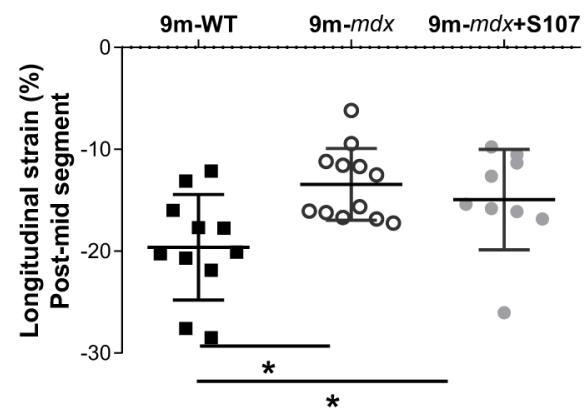

D

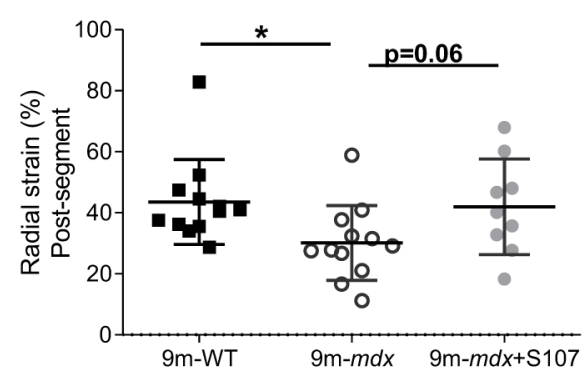

$\mathbf{F}$

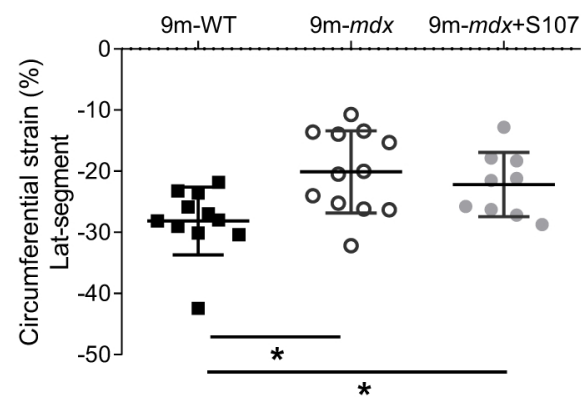

\section{Discussion}

Early detection of cardiac dysfunction and treatment is a priority for young patients with DMD. The present study is a preclinical prospective study that examined the effect of S107 (RyR2 stabilizer) on the evolution of early signs of LV dysfunction in young $m d x$ mice. Up to the age of 12 months, $m d x$ mice had preserved conventional ultrasound indexes of myocardial function. However, 2D strain analyses showed longitudinal, radial, and circumferential global peak systolic LV strain impairments as early as 9 months, with a greater magnitude at 12 months. The segmental 2D strain analysis revealed the early alteration of preferential segments, whose number increased with aging: posterior, lateral, and inferior LV segments. This decline in LV segmental strain was efficiently prevented by
4 months of S107 treatment only if administered in very young animals ( 2 months old).

We confirmed the interest of 2D strain analysis in the early detection of cardiomyopathy in DMD animal models. Despite of normal conventional ultrasound cardiac parameters, 2D global longitudinal, radial, and circumferential peak systolic strain of $\mathrm{LV}$ ventricle declined in $m d x$ mice as early as 9 months of age. We also observed several segmental decreases of peak systolic strain as early as 2 months of age that suggests some very early cardiac dysfunction. Most of those segmental decreases were either insufficient in the extent to affect the global peak systolic strains when all segments are averaged or were initially compensated by improvement of other segments, explaining why global peak systolic strains remained stable for a longer period. For example, the anteroseptal segment of the 
Fig. 4 Pharmacologic inhibition of RyR2 leak on regional systolic strain alterations in young $m d x$ mice. Four months of treatment with S107 (from 2 to 6 months old) prevented regional alterations in $m d x$ mice at 6 months of age. A Number of hypokinetic segments from the six segments obtained in longitudinal (Long), radial (Rad), and circumferential view in $m d x$ mice (light grey) and $m d x+$ S107 mice (black) compared with WT mice. TOTAL is the sum of hypokinetic segments obtained in the three views (out of 18 segments). The upper panel is a drawing illustrating the protocol. B-F Longitudinal posterior-mid strain (B), radial inferior $(\mathbf{C})$ and posterior (D) strains, and circumferential posterior (E) and lateral (F) strains in WT (black square, $\mathrm{n}=12$ ), $m d x$ (open circle, $\mathrm{n}=16$ ), and $m d x+\mathrm{S} 107$ (grey circle, $\mathrm{n}=10$ ) mice, one-way ANOVA $* p<0.05, * * * p<0.01$
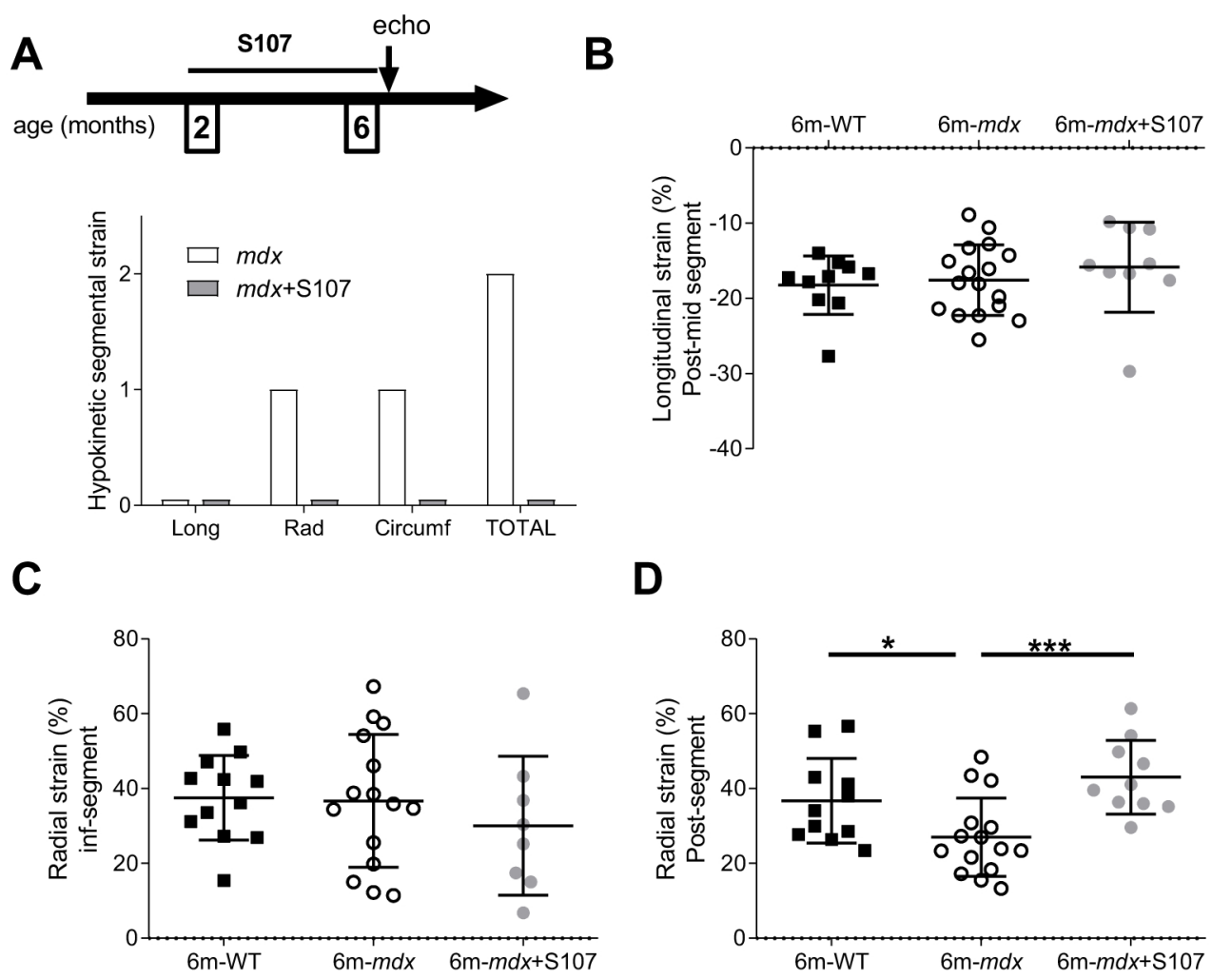

D

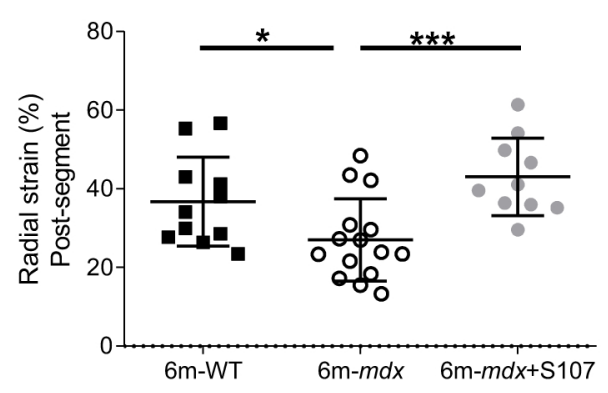

$\mathbf{E}$

$\mathbf{F}$

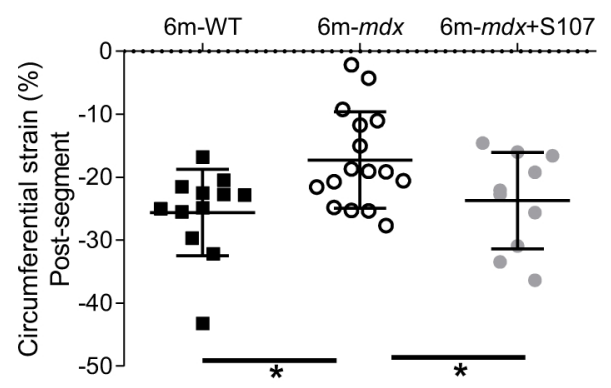

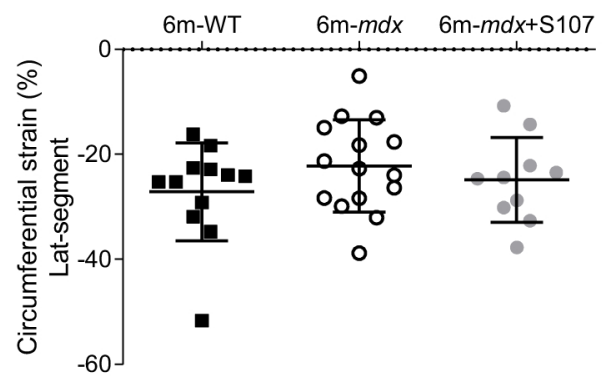

circumferential strain in $m d x$ mice tends to compensate the alteration of other segments between 2 and 6 months of age (Figure S1). At the age of 2 months, a transient significant decrease of global circumferential strain was observed, probably explained by hypokinetic circumferential lateral and posterior segments not compensated by the other segments. These results suggest that 2D strain analysis of cardiac function is more sensitive to detect early cardiac dysfunction, as previously published. Spurney et al. [18] showed significant decreased on LV radial strain after 9 months of age in male $m d x$ mice with mild cardiomyopathy compared to WT mice. Li et al. [8] showed longitudinal endomyocardial and radial global strain decreases from the age of 6 months in male and female $m d x$ mice. Longitudinal epimyocardial and circumferential endomyocardial global strain declined from 9 months and worsened with age. Furthermore, Li et al. showed, using 3D cardiac magnetic resonance tagging, a biphasic change in myocardial wall strain and torsion: despite a normal global ventricular function, $m d x$ mice experienced an initial increase at young age (2-month-old), followed by a progressive decrease at older ages [19].

Other DMD animal models like Canine $m d x$ showed similar preferential impaired LV segments: posterior segments were significantly decreased in carrier and affected dogs when segmental values were compared with normal dogs in Takano et al. study [7]. These myocardial strain patterns were also seen in previous clinical studies of DMD human patients. Mori et al. [20] showed a significant decrease on peak systolic radial strain of the posterior wall in DMD patients compared to controls. Ogata et al. [21] also showed abnormal strain profiles in the posterolateral wall of the LV in DMD patients with normal systolic function. Mertens 


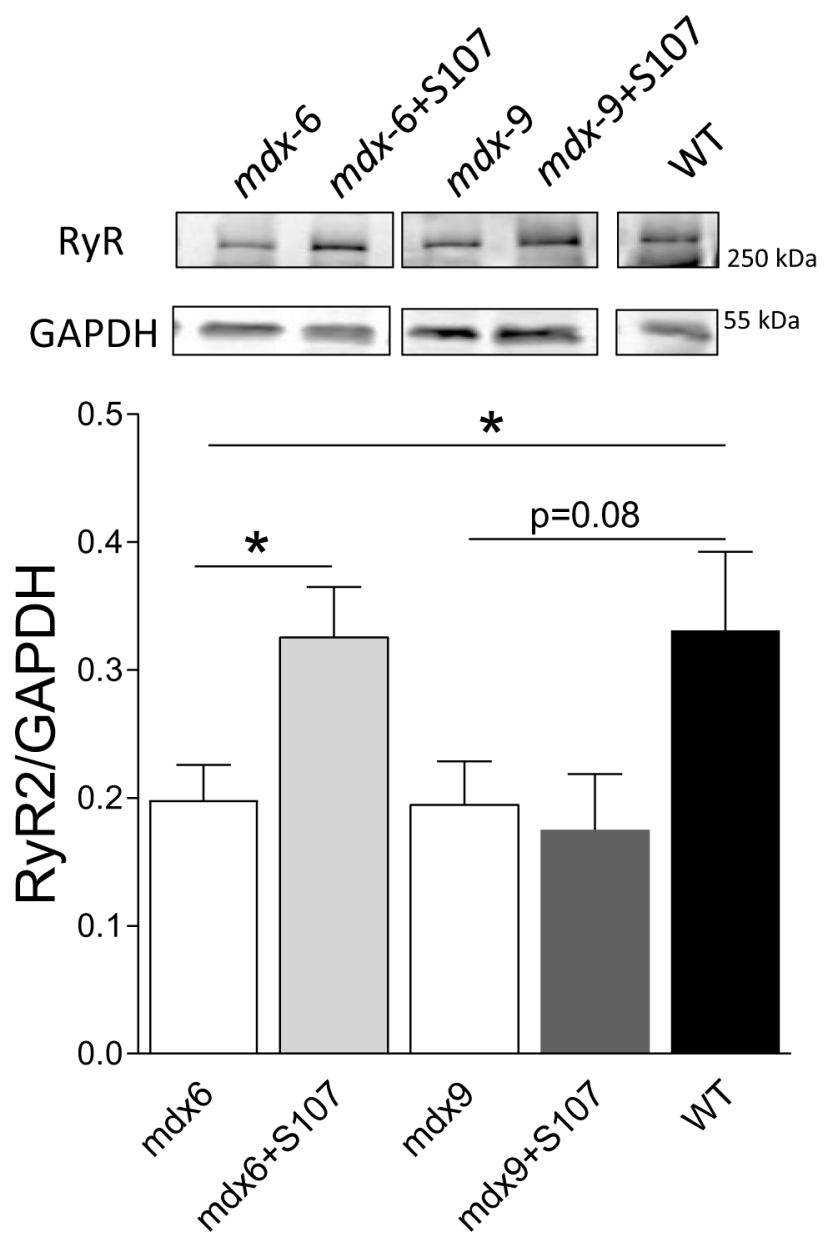

Fig. 5 Changes of the RyR2 macromolecular complex in the myocardium of $m d x$ mice and effect of the chronic treatment with S107. RyR2 content was quantified by Western blot in the LV of 6-monthold $m d x(m d x 6$, open bar, $\mathrm{n}=10)$ and $m d x+\mathrm{S} 107(m d x 6+\mathrm{S} 107$, grey bar, $\mathrm{n}=10)$, of 9-month-old $m d x(m d x 9$, open bar, $\mathrm{n}=5)$ and $m d x+\mathrm{S} 107(m d x 9+\mathrm{S} 107$, dark grey bar, $\mathrm{n}=5)$, and 12-month-old WT $(n=6) . * p<0.05$

et al. [6] demonstrated significant decreases on longitudinal and radial tissue velocities of the anterolateral and inferolateral LV walls in DMD patients with normal systolic function. Most recently, from our group, Amedro et al. [9] showed significant decrease in longitudinal, radial, and circumferential global LV strains in DMD children with normal systolic function compared to controls. Inferior, lateral, and anterolateral segments were preferentially impaired.

To our knowledge, there is no regional difference on dystrophin gene/protein expression in myocytes of the $m d x$ heart. However, we previously contributed to show that in different species, contractile properties in a normal heart are not uniform (differences between epi- and endomyocardial layers, LV basal and apical levels, left and right ventricles) and depend on the nature of myocardial stress (ischemic condition, pressure/volume overload, genetic disorder) [14,
22, 23]. We could hypothesize that a different level of fibrosis occurred among heart regions, in response to regional difference of shear stress [24]. To date, the regional disparity in regional strain in DMD is still unclear and under investigation.

The lack of dystrophin makes $m d x$ mice more vulnerable to mechanical stress and workload induced damage [25]. Calcium overload and mishandling due to membrane instability is a key mechanistic contributor to DMD disease onset and progression. Although they do not show signs of heart failure, young $m d x$ mice display abnormal $\mathrm{Ca}^{2+}$ homeostasis and $\mathrm{Ca}^{2+}$ dynamics [25]. This observation suggests that abnormalities in myocardial $\mathrm{Ca}^{2+}$ handling could play a role in the development of the cardiac damage, which precedes heart failure. The early alteration of contractility is consistent with the development of fibrotic lesions. Several publications showed higher fibrosis in $m d x$ compared with WT animals as early as $6-8$ months of age [19, 26, 27]. This indicates that early regional damages occur in the myocardium. The link between those regional damages and potential downstream signaling pathways such as the production of reactive oxygen species and Ryr2-dependant abnormal $\mathrm{Ca}^{2+}$ homeostasis remains to be explored in future studies.

Currently, there is no cure for DMD disease. Established small molecule therapy is limited to reduce the symptoms and hinder the mechanisms of disease progression in the heart. Chronic activation of the sympathoadrenergic system in $m d x /$ DMD may promote the progression of cardiomyopathy. Blain et al. [28] suggest that beta-blocker or ACE inhibitor treatment of 4-month-old $m d x$ mice over a 2-month period can improve some indexes of cardiac function assessed using cardiac MRI. Interestingly, combined treatment was not more effective. Spurney et al. [29] showed that chronic treatment with losartan from 3 to 9 months of age decreases cardiac and skeletal muscle fibrosis and improves cardiac systolic function in female $m d x$ mice.

In our study, we aimed to evaluate, with 2D-STE, the therapeutic effect of stabilizing RyR2 macrocomplex in the cardiac impairment of $m d x$ mice. We found that an earlier and longer S107 use (from 2- to 6-month-old) prevented the alteration of some LV segments and even normalized some segmental altered strains such as the circumferential strain of the posterior segment. These results suggest the involvement of the RyR2 alteration in dystrophin-deficient mice and its role in cardiac impairment. Other studies showed that in young animals, RyR2 was increased in 2-month-old [25] and 4-month-old $m d x$ hearts [8] compared with age-matched controls. Those changes coincided with a hypercontractile state due to hyperphosphorylation of multiple $\mathrm{Ca}^{2+}$ handling proteins induced by activation of the sympathoadrenergic system [30]. They also observed a higher basal $\mathrm{SR} \mathrm{Ca}^{2+}$ content in 4-month-old $m d x$ myocytes, suggesting that the increased $\mathrm{Ca}^{2+}$ current and SERCA activity overcome the 
leaking of $\mathrm{Ca}^{2+}$ out of the SR at this age. In our study, we found that RyR2 protein expression decreased from 6- to 9-month-old $m d x$ hearts suggesting a degradation process in old animals. This may also explain why the treatment with S107 was less efficient when the cure started at 6 months of age. An interesting feature of the S107 treatment was to normalize the level RyR2 expression when the treatment was used earlier, i.e., during the potential window of RyR2 overexpression. If the treatment was given too late, from 6 months of age, the beneficial effects on contractility and RyR2 expression were not observed.

\section{Limits}

Localization of segmental alteration of peak systolic strain in our study (i.e., posterior, inferior, and lateral LV wall) varies from its observed by Spurney et al. [18] (i.e., radial mid anterior LV wall). However, we used different software and Spurney et al. did not assess the LV posterior wall because of poor echogenicity issue.

All our analyses followed current echocardiographic guidelines and are blinded of mice's group, but we did not evaluate inter- and intra-observer reproducibility. However, we performed such a reliability analysis in a previously published study regarding 2D strain and small animals, with a good reproducibility [14].

The early treatment with S107 had beneficial effects on segmental LV strains usually altered on $m d x$ mice at 6 months of age. In the observational part of our study, we showed a significant decrease in the global strain from 9 months of age in $m d x$ mice. Thus, in future experiments, we should treat the animals until 12 months to see the effect of the treatment on improving the global strain parameter, indicative of a delay or prevention of the cardiac disease.

C57BL/10 $m d x$ mouse is the most extensively animal model used in the field of DMD. However, compared with DMD patients, $m d x$ mice present mild muscle pathology, no impact on lifespan, and delayed cardiomyopathy due to the upregulation of the dystrophin homolog utrophin [31]. New genetic mouse model, like DBA2/J background, has been recently developed to obtain a more severe muscle phenotype [32]. However, as other mice models, lifetime is not affected, suggesting other mechanisms of compensation. Furthermore, if inflammation and fibrosis occurred from 10-week-old, a spontaneous amelioration is observed as soon as 34 weeks of age and may present several biases in therapeutic studies [33]. This and our longer experience with our BL10- $m d x$ mice colony [34] explained why we choose the C57BL/10 $m d x$ mouse background for the present study.

Finally, the present work shows the interest in targeting early RyR2 leak in the DMD heart and opens possibilities for tests in animal models that mimic closely the human disease of DMD such as the golden retriever muscular dystrophy (GRMD) [23].

\section{Conclusion}

Our study is the first animal study to investigate with 2D-STE the therapeutic effect of a drug targeting the early signs of cardiomyopathy in DMD.

We believe that 2D strain should be a surrogate outcome in human DMD therapeutic studies.

Abbreviations 2D: Two-dimensional; DMD: Duchenne muscular dystrophy; STE: Speckle-tracking echocardiography; LV: Left ventricular; SR: Sarcoplasmic reticulum; WT: Wild-type; $m d x$ : X-linked muscular dystrophy; RYR2: Ryanodine receptor type 2

Funding This study was supported by the Association Française contre les Myopathies (AFM) (AL N¹5083).

Data Availability The data used to support the findings of this study are available from the corresponding author upon request.

\section{Declarations}

Ethics Approval Experiments were conducted in accordance with the European directive for the protection of animals used for scientific purposes and were approved by the ethical committee (Comité d'éthique pour l'expérimentation animale Languedoc-Roussillon, $\mathrm{n}^{\circ}$ CEEA-LR-12078).

Consent to Participate Not applicable.

Consent for Publication Not applicable.

Conflict of Interest The authors declare no competing interests.

\section{References}

1. Kamdar F, Garry DJ. Dystrophin-deficient cardiomyopathy. J Am Coll Cardiol. 2016;67:2533-46.

2. Birnkrant DJ, Bushby K, Bann CM, Apkon SD, Blackwell A, Colvin MK, et al. Diagnosis and management of Duchenne muscular dystrophy, part 3: primary care, emergency management, psychosocial care, and transitions of care across the lifespan. Lancet Neurol. 2018;17:445-55.

3. Spurney CF, McCaffrey FM, Cnaan A, Morgenroth LP, Ghelani SJ, Gordish-Dressman H, et al. Feasibility and reproducibility of echocardiographic measures in children with muscular dystrophies. J Am Soc Echocardiogr Off Publ Am Soc Echocardiogr. 2015;28:999-1008.

4. Taqatqa A, Bokowski J, Al-Kubaisi M, Khalil A, Miranda C, Alaksham $\mathrm{H}$, et al. The use of speckle tracking echocardiography for early detection of myocardial dysfunction in patients with Duchenne muscular dystrophy. Pediatr Cardiol. 2016;37:1422-8. 
5. Soslow JH, Xu M, Slaughter JC, Stanley M, Crum K, Markham LW, et al. Evaluation of echocardiographic measures of left ventricular function in patients with Duchenne muscular dystrophy: assessment of reproducibility and comparison to cardiac magnetic resonance imaging. J Am Soc Echocardiogr Off Publ Am Soc Echocardiogr. 2016;29:983-91.

6. Mertens L, Ganame J, Claus P, Goemans N, Thijs D, Eyskens B, et al. Early regional myocardial dysfunction in young patients with Duchenne muscular dystrophy. J Am Soc Echocardiogr Off Publ Am Soc Echocardiogr. 2008;21:1049-54.

7. Takano H, Fujii Y, Yugeta N, Takeda S, Wakao Y. Assessment of left ventricular regional function in affected and carrier dogs with Duchenne muscular dystrophy using speckle tracking echocardiography. BMC Cardiovasc Disord. 2011;11:23.

8. Li Z, Li Y, Zhang L, Zhang X, Sullivan R, Ai X, et al. Reduced myocardial reserve in young X-linked muscular dystrophy mice diagnosed by two-dimensional strain analysis combined with stress echocardiography. J Am Soc Echocardiogr Off Publ Am Soc Echocardiogr. 2017;30:815-827.e9.

9. Amedro P, Vincenti M, De La Villeon G, Lavastre K, Barrea $\mathrm{C}$, Guillaumont S, et al. Speckle-tracking echocardiography in children with Duchenne muscular dystrophy: a prospective multicenter controlled cross-sectional study. J Am Soc Echocardiogr Off Publ Am Soc Echocardiogr. 2019;32:412-22.

10. McGreevy JW, Hakim CH, McIntosh MA, Duan D. Animal models of Duchenne muscular dystrophy: from basic mechanisms to gene therapy. Dis Model Mech. 2015;8:195-213.

11. Stedman HH, Sweeney HL, Shrager JB, Maguire HC, Panettieri RA, Petrof B, et al. The mdx mouse diaphragm reproduces the degenerative changes of Duchenne muscular dystrophy. Nature. 1991;352:536-9.

12. Fauconnier J, Thireau J, Reiken S, Cassan C, Richard S, Matecki S, et al. Leaky RyR2 trigger ventricular arrhythmias in Duchenne muscular dystrophy. Proc Natl Acad Sci U S A. 2010;107:1559-64.

13. Nakamura A, Yoshida K, Takeda S, Dohi N, Ikeda S. Progression of dystrophic features and activation of mitogen-activated protein kinases and calcineurin by physical exercise, in hearts of $\mathrm{mdx}$ mice. FEBS Lett. 2002;520:18-24.

14. Chakouri N, Farah C, Matecki S, Amedro P, Vincenti M, Saumet L, et al. Screening for in-vivo regional contractile defaults to predict the delayed doxorubicin cardiotoxicity in juvenile rat. Theranostics. 2020;10:8130-42.

15. Petrof BJ, Shrager JB, Stedman HH, Kelly AM, Sweeney HL. Dystrophin protects the sarcolemma from stresses developed during muscle contraction. Proc Natl Acad Sci U S A. 1993;90:3710-4.

16. Johnstone VPA, Viola HM, Hool LC. Dystrophic cardiomyopathy - potential role of calcium in pathogenesis, treatment and novel therapies. Genes. 2017;8.

17. Andre L, Fauconnier J, Reboul C, Feillet-Coudray C, Meschin P, Farah C, et al. Subendocardial increase in reactive oxygen species production affects regional contractile function in ischemic heart failure. Antioxid Redox Signal. 2013;18:1009-20.

18. Spurney C, Yu Q, Nagaraju K. Speckle tracking analysis of the left ventricular anterior wall shows significantly decreased relative radial strain patterns in dystrophin deficient mice after 9 months of age. PLoS Curr. 2011;3:RRN1273.

19. Li W, Liu W, Zhong J, Yu X. Early manifestation of alteration in cardiac function in dystrophin deficient mdx mouse using 3D CMR tagging. J Cardiovasc Magn Reson Off J Soc Cardiovasc Magn Reson. 2009;11:40.
20. Mori K, Hayabuchi Y, Inoue M, Suzuki M, Sakata M, Nakagawa $\mathrm{R}$, et al. Myocardial strain imaging for early detection of cardiac involvement in patients with Duchenne's progressive muscular dystrophy. Echocardiogr Mt Kisco N. 2007;24:598-608.

21. Ogata H, Nakatani S, Ishikawa Y, Negishi A, Kobayashi M, Ishikawa $\mathrm{Y}$, et al. Myocardial strain changes in Duchenne muscular dystrophy without overt cardiomyopathy. Int J Cardiol. 2007;115:190-5.

22. Ait Mou Y, Lacampagne A, Irving T, Scheuermann V, Blot S, Ghaleh B, et al. Altered myofilament structure and function in dogs with Duchenne muscular dystrophy cardiomyopathy. J Mol Cell Cardiol. 2018;114:345-53.

23. Su JB, Cazorla O, Blot S, Blanchard-Gutton N, Ait Mou Y, Barthélémy I, et al. Bradykinin restores left ventricular function, sarcomeric protein phosphorylation, and e/nNOS levels in dogs with Duchenne muscular dystrophy cardiomyopathy. Cardiovasc Res. 2012;95:86-96.

24. Modesto K, Sengupta PP. Myocardial mechanics in cardiomyopathies. Prog Cardiovasc Dis. 2014;57:111-24.

25. Williams IA, Allen DG. Intracellular calcium handling in ventricular myocytes from mdx mice. Am J Physiol Heart Circ Physiol. 2007;292:H846-855.

26. Leone M, Magadum A, Engel FB. Cardiomyocyte proliferation in cardiac development and regeneration: a guide to methodologies and interpretations. Am J Physiol Heart Circ Physiol. 2015;309:H1237-1250.

27. Van Erp C, Loch D, Laws N, Trebbin A, Hoey AJ. Timeline of cardiac dystrophy in 3-18-month-old MDX mice. Muscle Nerve. 2010;42:504-13.

28. Blain A, Greally E, Laval SH, Blamire AM, MacGowan GA, Straub VW. Absence of cardiac benefit with early combination ACE inhibitor and beta blocker treatment in mdx mice. J Cardiovasc Transl Res. 2015;8:198-207.

29. Spurney CF, Sali A, Guerron AD, Iantorno M, Yu Q, GordishDressman $\mathrm{H}$, et al. Losartan decreases cardiac muscle fibrosis and improves cardiac function in dystrophin-deficient mdx mice. J Cardiovasc Pharmacol Ther. 2011;16:87-95.

30. Li Y, Zhang S, Zhang X, Li J, Ai X, Zhang L, et al. Blunted cardiac beta-adrenergic response as an early indication of cardiac dysfunction in Duchenne muscular dystrophy. Cardiovasc Res. 2014;103:60-71.

31. Kleopa KA, Drousiotou A, Mavrikiou E, Ormiston A, Kyriakides T. Naturally occurring utrophin correlates with disease severity in Duchenne muscular dystrophy. Hum Mol Genet. 2006;15:1623-8.

32. Coley WD, Bogdanik L, Vila MC, Yu Q, Van Der Meulen JH, Rayavarapu S, et al. Effect of genetic background on the dystrophic phenotype in mdx mice. Hum Mol Genet. 2016;25:130-45.

33. van Putten M, Putker K, Overzier M, Adamzek WA, PasteuningVuhman S, Plomp JJ, et al. Natural disease history of the D2-mdx mouse model for Duchenne muscular dystrophy. FASEB J Off Publ Fed Am Soc Exp Biol. 2019;33:8110-24.

34. Pons F, Robert A, Fabbrizio E, Hugon G, Califano JC, Fehrentz JA, et al. Utrophin localization in normal and dystrophin-deficient heart. Circulation. 1994;90:369-74.

Publisher's Note Springer Nature remains neutral with regard to jurisdictional claims in published maps and institutional affiliations. 